\title{
Divided attention in young drivers under the influence of alcohol
}

Freydier, $\mathrm{C}^{\mathrm{a}, \mathrm{b}}$, Berthelon, $\mathrm{C}^{\mathrm{a}}$, Bastien-Toniazzo, $\mathrm{M}^{\mathrm{b}}$, Gineyt, $\mathrm{G}^{\mathrm{c}}$.

${ }^{\mathrm{a}}$ French Institute of Science and Technology for Transport, Development and Networks

(Mechanisms of accidents Laboratory), 304 Chemin de la Croix Blanche, 13300 Salon de

Provence, France.

${ }^{\mathrm{b}}$ Aix-Marseille University (Laboratoire Parole \& Langage - UMR 7309) 5 Avenue Pasteur 13100 Aix en Provence, France

${ }^{\mathrm{c}}$ Department of Medical Information, Hospital center, 207 Avenue Julien Fabre 13300 Salon de Provence, France

chloe.freydier@lpl-aix.fr

catherine.berthelon@ifsttar.fr

mireille.bastien@lpl-aix.fr

ggineyt@ch-salon.fr

Corresponding author:

Chloé Freydier

Aix - Marseille Université

Pôle Psychologie

29 Avenue Robert Schuman

13090 Aix en Provence

Mail : chloe.freydier@lpl-aix.fr

Phone : 33 (0)4 13553721 


\section{Chloé Freydier}

\section{Ph.D Student}

French Institute of Science and Technology for Transport, Development and Networks

(Mechanisms of accidents Laboratory) \& Aix-Marseille University (Laboratoire Parole \&

Langage - UMR 7309)

304 Chemin de la Croix Blanche, 13300 Salon de Provence, France.

E-mail: chloe.freydier@lpl-aix.fr

Phone: 33 (0)4 13553721

\section{Catherine Berthelon}

Senior researcher, Ph.D

French Institute of Science and Technology for Transport, Development and Networks

(Mechanisms of accidents Laboratory)

304 Chemin de la Croix Blanche, 13300 Salon de Provence, France.

E-mail : catherine.berthelon@ifsttar.fr

Phone: 33 (0)4 90568630

\section{Mireille Bastien-Toniazzo}

Professor of Psychology

Aix-Marseille University (Laboratoire Parole \& Langage - UMR 7309)

5 Avenue Pasteur 13100 Aix en Provence, France

E-mail :mireille.bastien@lpl-aix.fr

Phone:33 (0)4 13553721

\section{Guy Gineyt}

\section{Medical Doctor}

Department of Medical Information, Hospital center

207 Avenue Julien Fabre 13300 Salon de Provence, France

E-mail :ggineyt@ch-salon.fr

Phone:33 (0)4 90449580. 


\begin{abstract}
Aim: The present research evaluates driving impairment linked to two crashes factors, divided attention task and alcohol, and determines whether it is higher for novice drivers than for experienced drivers. Method: Novice and experienced drivers participated in three experimental sessions in which blood alcohol concentrations (BACs) were $0.0 \mathrm{~g} / \mathrm{L}, 0.2 \mathrm{~g} / \mathrm{L}$ and $0.5 \mathrm{~g} / \mathrm{L}$. They performed a divided attention task with a main task of car-following task and an additional task of number parity identification. Driving performance, response time and accuracy on the additional task were measured. Results: ANOVA showed a driving impairment and a decrease in additional task performance from BAC of $0.5 \mathrm{~g} / \mathrm{L}$, particularly for novice drivers. Indeed, the latter adopt more risky behaviour such as tailgating. In the divided attention task, driving impairment was found for all drivers and impairment on information processing accuracy was highlighted, notably in peripheral vision. Impact of research: The divided attention task used here provides a relevant method for identifying the effects of alcohol on cognitive functions and could be used in psychopharmacological research.
\end{abstract}

Keywords: alcohol; divided attention; driving experience; simulator; car following

\title{
INTRODUCTION
}

Driving is a complex dynamic process control activity which requires accurate diagnosis of the situation and relevant decision making. Drivers have to select relevant information in traffic in order to anticipate and react effectively to sudden events. Many factors can influence driver behaviour and lead to crashes.

Among them, alcohol is recognized as one major factor of driving impairment and a linear relationship has been demonstrated between blood alcohol concentration (BAC) and crash risk, notably for young drivers (Peck, Gebers, Voas \& Romano, 2008 ; Zador, Krawchuk, \& Voas, 2000). Alcohol consumption impairs the skills necessary for safe driving (Moskowitz \& Fiorentino, 2000) and disrupts information processing (Harrison \& Fillmore, 2011; Fillmore, 
Freydier, C., et al., Divided attention in young drivers under the influence of alcohol, Journal of Safety Research (2014), http://dx.doi.org/10.1016/j.jsr.2014.02.003

2003). Driving performance is traditionally evaluated by measuring the standard deviation of lateral position (SDLP), which is defined as an indicator of the degree of adjustment that a driver implements to maintain a desired position within a lane (Harrison \& Fillmore, 2011). Studies indicate that, after alcohol intake, an increase in SDLP, a delay in reaction time to sudden events and an impairment of vigilance, visual and divided attention may occur (Meskali et al., 2009 ; Rakauskas et al., 2008 ; Koelaga, 1995).

The lack of experience is also recognized as a main factor of crash. Indeed, young drivers are widely over-represented in road accidents: in France for example, the lack of experience is the first cause of death among young drivers (ONISR, 2011). Many studies showed that the skills necessary for safe driving improve significantly with experience (Mc Cartt, Mayhew, Braitman, Ferguson, \& Simpson, 2009; Mayhew \& Simpson, 1995). The ability to control a vehicle is one of the first skills acquired by training and it is mastered in a few hours (Hall \& West, 1996), and then the perceptive and cognitive abilities can be developed. They are slower processes which include attentional allocation (Crundall \& Underwood, 1998), matching between task demands and driving skills (Brown \& Groeger, 1988), and contribute to drivers' potential ability to detect hazards. These crucial skills improve with experience (Deery, 1999; Underwood, 2007). Another factor of crash is driver distraction (Klauer, Dingus, Neale, Sudweeks, \& Ramsey, 2006) which can occur when the driver's attention is captured, intentionally or not, by a secondary task unrelated to the driving task (Regan, 2011). Actually, 19\% of drivers are engaged in an additional task like speaking, eating, drinking, smoking or using the mobile phone while driving (Gras et al., 2010). Performing an additional task is known to reduce driving performance and to increase reaction time (Andersen, Ni, Bian \& Kang, 2011 ; Cantin, Lavallière, Simoneau \& Teadsale, 2009 ; Bian, Kang \& Andersen, 2000). For example, using a mobile phone during a car-following task increases the mental load, which causes a delay in brake reaction time (Lamble, Kauranen, Laakso, \& Summala, 1999) and in the reaction time to headway changes (Brookhuis \& De Waard, 1994). Driver distraction by an additional visual task leads to an increase in mistake production 
Freydier, C., et al., Divided attention in young drivers under the influence of alcohol, Journal of Safety Research (2014), http://dx.doi.org/10.1016/j.jsr.2014.02.003

(Young \& Salmon, 2012) and when a novice driver is texting a message, he/she spends less time looking at the driving scene (Hosking, Young \& Regan, 2009). Performance impairment linked to an additional task, often measured in a simulated environment, is confirmed by a study carried out in real environment (Blanco, Biever, Gallagher \& Dingus, 2006) and can be interpreted in terms of limited information processing capacity (Kahneman, 1973). When a driver performs several tasks simultaneously, he/she is placed in a divided attention situation and he/she has to divide his/her attentional resources adequately between driving and the additional task. Thereby, the mental load related to the driving task increases when the driver has to divide his/her attentional resources between two tasks (Lemercier \& Cellier, 2008). It has recently been shown that the impairment linked to divided attention is even more pronounced when the driver is under the influence of alcohol (Harrisson \& Fillmore, 2011).

Alcohol, lack of experience and divided attention are thus recognized as three factors contributing to road accidents. Many studies have focused on the effects of each of these factors, but few have investigated their possible interaction. The aim of the present research is to evaluate driving impairment linked to divided attention and alcohol and to determine if this impairment is higher for novice drivers than for more experienced drivers.

\section{METHOD}

\section{Participants}

32 students divided into two groups depending on driving experience took part in this study. The first group consisted of 16 novice drivers ( 7 females and 9 males) aged 18, with less than 2 months of driving experience and less than $5000 \mathrm{~km}$. The second group consisted of 16 experienced drivers ( 8 female and 8 male) aged 21, with three years of driving experience and more than 20,000 km. All participants had obtained their driving license at the age of 18 . These two groups correspond to the beginning and end of the French 3-year probationary period. 
Participants underwent a medical examination in order to confirm their good physical condition, the absence of any sleep disorder and of any medical treatment at the time of their inclusion in the experiment and during the previous 15 days. Volunteers completed a questionnaire that provided demographic information as well as information on their drinking habits in order to control whether they had a substance abuse disorder. Only social drinkers, defined as individuals with moderate alcohol consumption (about two glasses of alcohol, not every day) chiefly in a social context, were included in this experiment.

To avoid any learning effect, participants received training before the experimental sessions. They provided written informed consent and received 120 Euros for their participation. The experimental protocol was approved by a local Ethics Committee.

\section{Experimental Design}

The driving experiment was carried out on the SIM2-IFSTTAR fixed base driving simulator equipped with an ARCHISISM object database (Espié, Gauriat \& Duraz, 2005) (See Figure 1a). The driving station includes one quarter of a vehicle. Drivers manage the vehicle by moving a steering wheel and manipulating the accelerator and brake pedals. The image projection surface spans $150^{\circ}$ horizontally and $40^{\circ}$ vertically. The images are generated at a frequency of $30 \mathrm{~Hz}$. A driving simulator was a relevant tool for our study because there is a large degree of similarity in the relationship between BAC levels and driving impairment observed in the driving simulator and in real driving (track test) (Helland et al., 2013).

Three experimental sessions were carried out according to a single-blind, balanced, cross-over design. Before each session, each participant had a drink (vodka and orange juice) in order to obtain a BAC of 0 (placebo), 0.2 or $0.5 \mathrm{~g} / \mathrm{L}$. BACs were measured with a breathalyzer (SD-400 DJP/LION) 15 min after alcohol intake, and then every 10 min until the desired BAC was obtained. All volunteers participated in the three sessions held at intervals of at least one day. 
Each session included three tasks and had a total duration of $30 \mathrm{~min}$. The order of presentation of the two single tasks was counterbalanced between each experimental session. A car-following single task was performed in order to assess the baseline driving performance. Drivers had to follow a lead vehicle while keeping constant distance from this vehicle. In order to prevent learning effects, the lead vehicle speed was varied with sixteen accelerations and sixteen decelerations with either high or low amplitude. The driver was placed in the middle lane of a three-lane road so that his/her visual environment was perfectly symmetrical. A single task of number parity identification was carried out in order to ensure that its cognitive cost was similar for experienced and novice drivers. This number parity identification task required to identify even and odd numbers and to activate the right control of the steering wheel if the target was even or the left control if the target was odd. A three-figure number appeared at 1.5 second to 2.5 second intervals with the duration of 400 milliseconds, in either the central or peripheral visual field of the driver. Then, the volunteers performed a divided attention task : they were asked to simultaneously perform a car- following task and identify the parity of numbers appearing in either their central or their peripheral visual field (left or right) (See Figure 1b). The interference related to the divided attention task was computed and compared with baseline measures obtained in single tasks.

The main driving task was specifically chosen on the basis of a previous study showing that a carfollowing situation involves behavioural impairment in case of alcohol intoxication (Meskali et al., 2009) and the secondary task was chosen outside the driving context in order to avoid prospective learning effects linked to driving experience. In addition, while driving most of information used is visual information (Sivak, 1996). The interference between the two tasks should be particularly pronounced because both tasks use the same perceptual channel (visual), and therefore, mobilize the same resources (Wickens 1984, 2002).

Figure 1 a. Driving simulator; b. Visual scenario of divided attention task 


\section{Measurements}

Driving performance was evaluated using lateral and longitudinal vehicle control. Lateral control was assessed by measuring SDLP, which reflects lane-keeping skills. Many research studies have established that SDLP is a valid and sensitive indicator of impaired behaviour (Harrison \&

Fillmore, 2005 ; Rakauskas et al., 2008 ; Shinar, Tractinsky \& Compton, 2005) and an increase in SDLP indicates an impairment of lateral control ability (Harrisson \& Fillmore, 2011).

Longitudinal control was assessed by measuring the minimum inter-vehicular distance (min IVD) e.g. the minimum distance adopted between the rear of the lead vehicle and the front of the following vehicle.

The reaction time (RT) and the percentage of correct responses (CR) on the additional task were also assessed.

\section{Data Analyses}

Results from the divided attention task were compared to results obtained in the reference tasks (car-following single task of and single task of number parity identification).

Firstly, the effects of BAC, task and driving experience on driving performance were analyzed by 2 (driving experience)* $3(\mathrm{BAC}) * 2$ (task) repeated measures analysis of variance (ANOVAs). Secondly the effects of BAC, task, number location and driving experience on response time and accuracy of number parity identification were analyzed by a 2 (driving experience) * $3(\mathrm{BAC}) * 2$ (task) * 3 (number location) ANOVAs. Statistical analyses were performed using Statistica software. The data were tested for a significance threshold of $\mathrm{p}<0.05$. Bonferroni post-hoc tests were subsequently used for pair-wise comparisons. 


\section{RESULTS}

\section{Driving Performance}

Standard Deviation of Lateral Position

As expected, ANOVA showed a significant main effect of driving experience $(\mathrm{F}(1,30)=3.92, \mathrm{p}$ $<0.05$ ). SDLPs were higher for novice drivers than for experienced drivers (respectively, $\mathrm{M}=$ $14.72 \mathrm{~cm} ; \mathrm{SD}=4.2$ and $\mathrm{M}=12.71 \mathrm{~cm} ; \mathrm{SD}=3.4)$.

A significant main effect of task was also highlighted $(\mathrm{F}(1,30)=13.64, \mathrm{p}<0.001)$. Overall, SDLPs were higher in a divided attention task than in a car-following single task (respectively, $\mathrm{M}$ $=14.4 \mathrm{~cm} ; \mathrm{SD}=3.8$ and $\mathrm{M}=13.07 \mathrm{~cm} ; \mathrm{SD}=3.3)$.

In accordance with our assumption, ANOVA revealed a significant main effect of $\operatorname{BAC}(\mathrm{F}(2,60)$ $=9.5, \mathrm{p}<0.001)$. SDLPs for drivers with a BAC of $0.5 \mathrm{~g} / \mathrm{L}(\mathrm{M}=14.95 \mathrm{~cm} ; \mathrm{SD}=4)$ were higher than for those with a BAC of $0.2 \mathrm{~g} / \mathrm{L}(\mathrm{M}=13.47 \mathrm{~cm} ; \mathrm{SD}=4)$ and $0.0 \mathrm{~g} / \mathrm{L}(\mathrm{M}=12.7 \mathrm{~cm} ; \mathrm{SD}=$ 2.8). No significant difference was found between the placebo and a BAC of $0.2 \mathrm{~g} / \mathrm{L}$. A trend toward a significant interaction between BAC and task was found $(\mathrm{F}(2,60)=2.44, \mathrm{p}=$ 0.09). Pair-wise comparisons showed that the increase in SDLPs in a divided attention task compared to that in a single task was only significant for a BAC of $0.5 \mathrm{~g} / \mathrm{L}$ (respectively, $\mathrm{M}=$ $16.07 \mathrm{~cm} ; \mathrm{SD}=4.5$ and $\mathrm{M}=13.83 \mathrm{~cm} ; \mathrm{SD}=3.5)$. When drivers with a $\mathrm{BAC}$ of $0.5 \mathrm{~g} / \mathrm{L}$ were involved in a divided attention task, their SDLPs were significantly higher than in all other conditions of BAC and task (see Figure 2).

No significant interaction was found between driving experience and $\operatorname{BAC}(\mathrm{F}(2,60)=1.68, \mathrm{p}=$ $0.19)$, neither between driving experience and task $(\mathrm{F}(1,30)=0.48, \mathrm{p}=0.49)$. 
Minimum Inter-Vehicular Distance

A significant main effect of task was demonstrated $(\mathrm{F}(1,30)=7.38, \mathrm{p}<0.05)$. Overall, the minimum Inter-Vehicular Distance (min-IVD) was shorter in a divided attention task than in a car-following single-task (respectively, $\mathrm{M}=17.55 \mathrm{~m} ; \mathrm{SD}=4.5$ and $\mathrm{M}=18.73 \mathrm{~m} ; \mathrm{SD}=4.6$ ). An interaction between task and driving experience $(F(1,30)=6.9, p<0.05)$ showed that a decrease in min IVD in a divided attention task was only significant for experienced drivers (See Figure 3). ANOVA revealed a significant main effect of BAC on $\min \operatorname{IVD}(F(2,60)=16.36, \mathrm{p}<0.001)$. Overall, the min IVD of drivers with a BAC of $0.5 \mathrm{~g} / \mathrm{L}(\mathrm{M}=16.22 \mathrm{~m} ; \mathrm{SD}=4.4)$ were shorter than those of drivers with a BAC of $0.2 \mathrm{~g} / \mathrm{L}(\mathrm{M}=18.85 \mathrm{~m} ; \mathrm{SD}=4.4)$ and with placebo $(\mathrm{M}=$ $19.35 \mathrm{~m} ; \mathrm{SD}=4.4)$. No significant difference was found between the placebo and a BAC of 0.2 $\mathrm{g} / \mathrm{L}$. In accordance with our assumption, a significant interaction between BAC and driving experience $(\mathrm{F}(2,60)=6.6, \mathrm{p}<0.01)$ revealed that the decrease in min IVD with alcohol was only significant for novice drivers (See Figure 4).

Figure 3 Minimum Inter-vehicular Distance depending on Task and Driving Experience

Figure 4 Minimum Inter-vehicular Distance depending on BAC and Driving Experience

\section{Additional Task Performance}

Response time

As expected, a significant main effect of driving experience was found $(F(1,30)=4.43, p<.05)$.

Overall, novice drivers had slower response times than experienced drivers (respectively, $\mathrm{M}=$ $0.88 \mathrm{~s} ; \mathrm{SD}=0.12$ and $\mathrm{M}=0.84 \mathrm{~s} ; \mathrm{SD}=0.1)$. 
ANOVA showed a significant main effect of task $(\mathrm{F}(1,30)=11.01, \mathrm{p}<.005)$. Overall, drivers

had slower response times in a single task of number identification than in a divided attention task (respectively, $\mathrm{M}=0.87 \mathrm{~s} ; \mathrm{SD}=0.1$ and $\mathrm{M}=0.85 \mathrm{~s} ; \mathrm{SD}=0.10$ ).

A significant main effect of number location was also found $(\mathrm{F}(2,60)=629.54, \mathrm{p}<.001)$.

Drivers had slower response times when a number appeared in the peripheral visual field -right $(\mathrm{M}=0.93 \mathrm{~s} ; \mathrm{SD}=0.09)$ and left $(\mathrm{M}=0.90 \mathrm{~s} ; \mathrm{SD}=0.09)-$ than in the central visual field $(\mathrm{M}=$ $0.77 \mathrm{~s} ; \mathrm{SD}=0.08$ ). Response time difference between right and left peripheral identification was significant.

A trend toward a significant interaction between number location and driving experience was obtained $(\mathrm{F}(2,60)=2.49, \mathrm{p}=0.09)$ showing that only experienced drivers' response times were slower when a number appeared in their right peripheral visual field than in their left peripheral visual field (see Figure 5).

No significant main effect of alcohol on response time was found, or any interactive effect between $\mathrm{BAC}$ and driving experience $(\mathrm{F}(2,60)=0.86, \mathrm{p}=.43), \mathrm{BAC}$ and task $(\mathrm{F}(2,60)=0.21$, $315 \mathrm{p}=.81), \mathrm{BAC}$ and number location $(\mathrm{F}(4,120)=0.52, \mathrm{p}=.72)$.

Figure 5 Reaction Time depending on Driving Experience and Number location

Accuracy

In accordance with our assumption, ANOVA revealed a significant main effect of $\operatorname{BAC}(\mathrm{F}(2,60)$ $=4.03, \mathrm{p}<.05)$. The correct response percentage was lower for drivers with a BAC of $0.5 \mathrm{~g} / \mathrm{L}(\mathrm{M}$ $=86.8 \% ; \mathrm{SD}=8.6)$ than for drivers with a BAC of $0.2 \mathrm{~g} / \mathrm{L}(\mathrm{M}=89 \% ; \mathrm{SD}=9)$ and $0.0 \mathrm{~g} / \mathrm{L}(\mathrm{M}$ $=89.6 \% ; \mathrm{SD}=7.4)$.

A significant main effect of number location was found $(\mathrm{F}(2,60)=81.27, \mathrm{p}<.001)$. Pair-wise comparisons indicated that the correct response percentage was lower when a number appeared in 
the peripheral visual field, either the right $(\mathrm{M}=87.2 \% ; \mathrm{SD}=9)$ or left $(\mathrm{M}=81.7 \% ; \mathrm{SD}=11.8)$ side, than when it appeared in the central visual field $(\mathrm{M}=96.1 \% ; \mathrm{SD}=4.3)$. Moreover, the percentage of correct responses in right peripheral vision was significantly lower than that in left peripheral vision.

A significant interaction between BAC and number location $(\mathrm{F}(4,120)=3.1, \mathrm{p}<.05)$ indicated that the decrement of correct response percentage for the drivers with the highest BAC was only significant when the number appeared in the peripheral visual field (right and left side). In addition, a significant decrease in the correct response percentage was found for drivers with a BAC of $0.5 \mathrm{~g} / \mathrm{L}$ compared to drivers with a BAC of $0.2 \mathrm{~g} / \mathrm{L}$ only when a number appeared in the right peripheral visual field (see Figure 6).

ANOVA also revealed a significant main effect of task, $(\mathrm{F}(1,30)=28.88, \mathrm{p}<.001)$ showing a decrease in correct response percentage in a divided attention task compared to baseline performance on a single task of number parity identification (respectively, $\mathrm{M}=86.2 \%$; $\mathrm{SD}=9.7$ and $\mathrm{M}=90.8 \% ; \mathrm{SD}=7)$.

A significant interaction between task and number location $(F(2,60)=21.76, p<.001)$ revealed that this decrease in correct response percentage for divided attention task was only significant when a number appeared in the right peripheral visual field (See Figure 7).

Figure 6 Correct responses depending on BAC and Number location.

Figure 7 Correct responses depending on Task and Number location

\section{DISCUSSION}

In the present study, the relationships between BAC, divided attention and driving experience on simulated driving performance were investigated. The hypothesis was that the combination of 
alcohol and divided attention task would interact to impair driving performance, especially for novice drivers.

\section{Alcohol effects}

Analyses revealed that alcohol consumption impaired lateral and longitudinal control from a BAC of $0.5 \mathrm{~g} / \mathrm{L}$. As for lateral control measured by SDLP, our findings are consistent with those of previous studies in which a dose-response relationship between BAC level and SDLP was demonstrated (Helland et al., 2013 ; Harrisson \& Fillmore, 2011 ; Meskali et al., 2009). Therefore, our data confirm that SDLP is a valid and sensitive indicator of driving impairment related to alcohol consumption. Overall, alcohol impairs lateral control independent of driving experience. It seems worthwile to compare this result with those obtained by Meskali et al. (2011) because both studies used the same driving simulator and a car-following task. In Meskali et al (2011), the SDLP increase was found significant only for a BAC of $0.8 \mathrm{~g} / \mathrm{L}$, but subjects were experienced drivers with a mean age higher than that of our participants. This might suggest that lateral control impairment appeared earlier for young drivers, for a BAC as low as $0.5 \mathrm{~g} / \mathrm{L}$, but this hypothesis has yet not been tested statistically. As for longitudinal control measured by min IVD, only novice drivers with a BAC of $0.5 \mathrm{~g} / \mathrm{L}$ adopted shorter inter-vehicular distances, that is to say, alcohol impairs the longitudinal control ability of novice drivers but not that of experienced drivers. Thus, min IVD is a relevant parameter to investigate specifically novice drivers' skills and differentiate novice drivers from experienced drivers.

As for additional task performance, cognitive processing accuracy - but not response time - was impaired from a BAC of $0.5 \mathrm{~g} / \mathrm{L}$. This differential effect of alcohol depending on the parameters measured was explained by Schweizer and Vogel-Sprott (2008), who showed that information processing speed tends to develop acute alcohol tolerance, but not accuracy. Regarding accuracy, alcohol impairment occurred only when a number appeared in the peripheral visual field. This result replicates the common effect of tunnel vision induced by alcohol, as suggested by the 
Freydier, C., et al., Divided attention in young drivers under the influence of alcohol, Journal of Safety Research (2014), http://dx.doi.org/10.1016/j.jsr.2014.02.003

inability of drivers to disengage their attention from their central visual field toward their peripheral visual field (Do Canto-Pereira, de PA David, Machado-Pinheiro, \& Ranvaud, 2007). In spite of a clear dose-response effect, no significant driving impairment linked to a low dose of alcohol (BAC of $0.2 \mathrm{~g} / \mathrm{L}$ ) was found. Epidemiological studies indicated that the crash severity increases for BACs as low as $0.1 \mathrm{~g} / \mathrm{L}$ (Phillips \& Brewer, 2011) and the fatal crash risk is twice for a BAC of $0.2 \mathrm{~g} / \mathrm{L}$ compared to a BAC of $0.0 \mathrm{~g} / \mathrm{L}$, especially for young novice drivers (Peck et al., 2008). Two hypotheses could explain this result. Firstly, it might suggest that driving impairment induced by alcohol occurs for a BAC higher than $0.2 \mathrm{~g} / \mathrm{L}$, as in other experimental studies that reveal driving impairment only from $0.3 \mathrm{~g} / \mathrm{L}$ (Schnabel, Hargutt, \& Krueger, 2010 for a revue). Thereby, this research contributes to specify the minimum level of BAC that impairs driving skills. Indeed, the BAC limit for safe driving could be situated between $0.2 \mathrm{~g} / \mathrm{L}$ and 0.3 g/L. Moreover, some countries have reduced the tolerated BAC down to $0.2 \mathrm{~g} / \mathrm{L}$ for specific populations such as novice and professional drivers and they have recorded a decrease in crash number (Andreuccetti et al, 2011 ; Dupont, Martensen \& Silverans, 2000). Secondly, another explanation concerns task characteristics. In our study, the driving scenario was relatively easy and involved only a straight road. Since novice drivers are already in difficulty in a complex situation without alcohol (Damn, Nachtergaele, Meskali, \& Berthelon, 2011) and that alcohol especially impairs complex tasks (Schnabel et al, 2010) it might be that a more complex task could highlight driving impairment of novice drivers with low doses of alcohol. Thus, future research should include more complex situations to refine these results.

\section{Divided attention task effects}

Performance impairment was observed in a divided attention task compared to the reference single tasks, that is, car-following task or number identification task. Overall, driving performance (SDLP) and accuracy (CR) on additional task were impaired in a divided attention task, whatever the driving experience. This result confirmed that performing an additional task while driving 
leads to a driving impairment and disrupts the information processing. The difficulties observed in a divided attention task can be explained by the limited information processing capacity. Indeed, the amount of attentional resources mobilized in a divided attention task increases compared to each task alone and can exceed the amount of available resources (Kahneman, 1973).

As for longitudinal control, only the min IVD of experienced drivers decreased in a divided attention task compared to a car-following single task. The min IVD of novice drivers also decreased in a divided attention task compared to baseline measures obtained in a car-following single task but this difference was not significant, certainly on account of the high heterogeneity of performance. In addition, our volunteer drivers were all students, which can reduce the difference between the two groups. It is actually well recognized that student drivers with high educational background are less involved in crashes than the general population at the same age (Murray, 1998).

Regarding additional task performance, drivers had a lower correct response percentage in a divided attention task compared to a single task of number parity identification only when the numbers appeared in right peripheral visual field. Response time was also impaired in right peripheral vision compared to left peripheral vision, whatever the task. These results highlight differences in information processing depending on the number location, and notably depending on the side of the peripheral visual field. Response time difference depending on peripheral side was only found for experienced drivers, suggesting that it develops gradually with driving experience. Indeed, when the task is more demanding, e.g. in a divided attention task or when the driver is novice, his/her gaze is focused on his/her central visual field (Lemercier \& Cellier, 2008 ; Williams, 1995).

Surprisingly, subject response times were slower for single task of number parity identification than for divided attention task. Note that number identification task responses were given with vehicle commands situated near the steering wheel and that different hand positions were observed depending on the task. Indeed, in single task of number parity identification, 
participants' hand positions were variable whereas in divided attention task, their hands were kept on the steering wheel. Hand position in space may be a relevant index of load related to the task demands and it seems that future research studies should have a control on this factor.

\section{Driving experience effects}

Finally, results revealed that SDLP of novice drivers was higher than those of experienced drivers, which reflects a poorer lateral vehicle control. This result confirms the assumption that driving skills of novice drivers are lower than those of experienced drivers, and is consistent with previous studies showing that experienced drivers, contrary to novice drivers, exhibited an active control of their lateral position during urban scenarios (Damn et al., 2011). In a similar way, novice drivers' response times on additional task were slower than those of experienced drivers, which can be explained by the involvement of different cognitive processes depending on driving experience. Indeed, the main car-following task involved controlled processes for novice drivers, while these processes become automatic with experience. As a consequence, this task mobilized the quasi totality of attentional resources for novice drivers, and few resources were available to process an additional task.

\section{CONCLUSIONS}

To sum up, our results show that, classically, alcohol, divided attention and lack of experience were independently related to driving impairment. In addition, our hypothesis is also confirmed: alcohol and driving experience interact to lead to a higher driving impairment for young novice drivers than for young experienced drivers. It is particularly interesting because what was used to differentiate novice and experienced drivers was only three years' driving experience and age. As a result, this research contributes to improve the knowledge on the specific probationary period applied in France. In addition, the divided attention task used here provides a relevant method to 
isolate and identify the effects of acute alcohol intoxication on cognitive functions and could be used in psychopharmacological research.

\section{ACKNOWLEDGEMENTS}

This research was supported in part by IFSTTAR, French Institute of Science and Technology, Transport and Networks. We thank Isabelle Aillerie for the establishment of scenario images and Virginie Etienne for her constructive suggestions. We also thank all the participants for their cooperation.

\section{REFERENCES}

Andersen, G. J., Ni, R., Bian, Z., \& Kang, J. (2011). Limits of spatial attention in three-dimensional space and dual task driving performance. Accident Analysis \& Prevention, 43(1), 381-390. doi:10.1016/j.aap.2010.09.007

Andreuccetti, G., Carvalho, H.B., Cherpitel, C.J., Ye, Y., Ponce, J.C., Kahn, T., Leyton, V. (2011). Reducing the legal blood alcohol concentration limit for driving in developing countries : a time for change? Results and implications derived from a time-series analysis (2001-10) conducted in Brazil. Addiction, 106, 2124-2131. doi: $310.1111 / j .1360-0443.2011 .03521 \mathrm{x}$

Bian, Z., Kang, J. J., \& Andersen, G. J. (2010). Changes in Extent of Spatial Attention with Increased Workload in Dual-Task Driving. Transportation Research Record: Journal of the Transportation Research Board, 2185(-1), 8 14. doi:10.3141/2185-02 483

Blanco, M., Biever, W. J., Gallagher, J. P., \& Dingus, T. a. (2006). The impact of secondary task cognitive processing demand on driving performance. Accident ; analysis and prevention, 38(5), 895-906.

doi:10.1016/j.aap.2006.02.015

Brookhuis, K.A., De Waard, D. (1994). Measuring driving performance by car-following in traffic. Ergonomics 37 (3), 427-434.

Brown, I.D., Groeger, J.A. (1988). Risk perception and decision taking during the transition between novice and experienced driver status. Ergonomics, 31 (4), 585-597.

Cantin, V., Lavallière, M., Simoneau, M., \& Teasdale, N. (2009). Mental workload when driving in a simulator: effects of age and driving complexity. Accident ; analysis and prevention, 41(4), 763-71. doi:10.1016/j.aap.2009.03.019

Crundall, D.E., Underwood, G. (1998). Effects of experience and processing demands on visual information acquisition in drivers. Ergonomics, 41(4), 448-458. 
Freydier, C., et al., Divided attention in young drivers under the influence of alcohol, Journal of Safety Research (2014), http://dx.doi.org/10.1016/j.jsr.2014.02.003

Damn, L., Nachtergaele, C., Meskali, M., and Berthelon, C. (2011). The evaluation of traditional and early driver training with simulated accident scenarios. Human Factors 53 (4), 323-337.

Deery, H. A. (1999). Hazard and Risk Perception among Young Novice Drivers, 30(4), 225-236.

Do Canto-Pereira, L. H. M., De P A David, I., Machado-Pinheiro, W., \& Ranvaud, R. D. (2007). Effects of acute alcohol intoxication on visuospatial attention. Human \& experimental toxicology, 26(4), 311-9. doi:10.1177/0960327106070490

Dupont, E., Martensen, H., Silverans, P. (2010). Abaissement du taux d'alcool autorisé pour les conducteurs novices et les conducteurs de grands véhicules : $0.2 \%$. Institut Belge pour la Sécurité Routière - Centre de connaissance, Brussels, Belgium.

Espié, S., Gauriat, P., and Duraz, M. (2005). Driving simulators validation : The issue of transferability of results acquired on simulator. Proceeding of Driving Simulation Conference, Orlando, Etats-Unis.

Fillmore, M.T. (2003). Drug abuse as a problem of impaired control ; current approaches and findings. Behavioral. Cognitive Neuroscience Review 2, 179-197.

Gras, M.E., Planes, M., Font-Mayolas, S., Sullman, M.J.M., Jimenez, M., and Prat, F. (2010). Driving distractions in Spain. Proceedings of Driving Simulation Conference, Paris, France.

Hall, J., West, R. (1996). Role of formal instruction and informal practice in learning to drive. Ergonomics, 39 (4), 693-706.

Harrison, E.L.R, Fillmore, M.T. (2005). Are bad drivers more impaired by alcohol? Sober driving predicts impairment from alcohol in a simulated driving task. Accident Analysis and Prevention 37 (5), 882-889. doi: 10.1016/j.drugalcdep.2011.01.002

Harrison, E. L. R., \& Fillmore, M. T. (2011). Alcohol and distraction interact to impair driving performance. Drug and alcohol dependence, 117(1), 31-7. doi:10.1016/j.drugalcdep.2011.01.002

Helland, A., Jenssen, G. D., Lervåg, L.-E., Westin, A. A., Moen, T., Sakshaug, K., Lydersen, S., et al. (2013). Comparison of driving simulator performance with real driving after alcohol intake: a randomised, single blind, placebo-controlled, cross-over trial. Accident ; analysis and prevention, 53, 9-16. doi:10.1016/j.aap.2012.12.042

Hosking, S. G., Young, K. L., \& Regan, M. a. (2009). The Effects of Text Messaging on Young Drivers. Human Factors: The Journal of the Human Factors and Ergonomics Society, 51(4), 582-592. doi: $10.1177 / 0018720809341575$

Kahneman, D. (1973). Attention and Effort. Englewood Cliffs, NJ: Prentice-All.

Koelaga, H. (1995). Alcohol and vigilance performance: a review. Psychopharmacology 118, 233-249. 
Freydier, C., et al., Divided attention in young drivers under the influence of alcohol, Journal of Safety Research (2014), http://dx.doi.org/10.1016/j.jsr.2014.02.003

Klauer, S.G., Dingus, T.A., Neale, V.L., Sudweeks, J.D., Ramsey, D.J. (2006). The impact of driver inattention on near-crash/crash risk: an analysis using the 100-car naturalistic driving study data. Report No. DOT HS 810 594, National Highway Traffic Safety Administration, Washington, D.C.

Lamble, D., Kauranen, T., Laakso, M., \& Summala, H. (1999). Cognitive load and detection thresholds in car following situations: safety implications for using mobile (cellular) telephones while driving. Accident ; analysis and prevention, 31(6), 617-23. Retrieved from http://www.ncbi.nlm.nih.gov/pubmed/10487336

Lemercier, C., Cellier, J.M. (2008). Les défauts de l'attention en conduite automobile : inattention, distraction et interférence. Le Travail Humain, 71, 271-296.

Mayhew, D.R. and Simpson, H.M. The role of driving experience: Implications for the training and licensing of new drivers. Toronto, ON: Insurance Bureau of Canada, (1995).

Mc Cartt, A.T., Mayhew, D.R., Braitman, K.A., Ferguson, S.A., Simpson, H.M. (2009). Effects of age and experience on young driver crashes : review of recent literature. Traffic Injury Prevention , 10 (3), 209-219. doi: 10.1080/15389580802677807.

Meskali, M., Hirt, S., Aillerie, I., Gineyt, G., Louveton, N. and Berthelon, C. (2009). Effect of moderated doses of alcohol on behavior of drivers confronted to simulated scenarios of accident. Advance in Transportation Studies an International Journal, Section B, 25, 91-96.

Moskowitz, H., Fiorentino, D. A review of the scientific literature regarding the effects of alcohol on drivingrelated behavior at blood alcohol concentrations of 0.08 grams per decileter and lower. Report no. DOT HS 809 028.U.S. Department of Transportation, Washington, DC, (2000).

Murray, A. (1998). The home and school background of young drivers involved in traffic accidents. Accident Analysis \& Prevention, 30 (2), 169-182.

Observatoire National Interministériel de la Sécurité Routière (2011). La sécurité routière en France. Bilan de l'année 2011.

Peck, R.C., Gebers, M.A., Voas, R.B., and Romano, E. (2008). The relationship between blood alcohol concentration (BAC), age, and crash risk. Journal of Safety Research 39 (3), 311-319.

Phillips, D. P., \& Brewer, K. M. (2011). The relationship between serious injury and blood alcohol concentration (BAC) in fatal motor vehicle accidents: $\mathrm{BAC}=0.01 \%$ is associated with significantly more dangerous accidents than BAC $=0.00 \%$. Addiction (Abingdon, England), 106(9), 1614-22. doi:10.1111/j.13600443.2011.03472.x 
Freydier, C., et al., Divided attention in young drivers under the influence of alcohol, Journal of Safety Research (2014), http://dx.doi.org/10.1016/j.jsr.2014.02.003

Rakauskas, M.E., Ward, N.J., Boer, E.R., Bernat, E.M., Cadwallader, M. and Patrick, C.J. (2008). Combined effects of alcohol and distraction on driving performance. Accident Analysis and Prevention 40 (5), $1742-$ 1749.

Regan, M. a, Hallett, C., \& Gordon, C. P. (2011). Driver distraction and driver inattention: definition, relationship and taxonomy. Accident ; analysis and prevention, 43(5), 1771-81. doi:10.1016/j.aap.2011.04.008

Schweizer, T. a, \& Vogel-Sprott, M. (2008). Alcohol-impaired speed and accuracy of cognitive functions: a review of acute tolerance and recovery of cognitive performance. Experimental and clinical psychopharmacology, 16(3), 240-50. doi:10.1037/1064-1297.16.3.240

Shinar, D., Tractinsky, N., \& Compton, R. (2005). Effects of practice, age, and task demands, on interference from a phone task while driving. Accident ; analysis and prevention, 37(2), 315-26. doi:10.1016/j.aap.2004.09.007

Schnabel, E., Hargutt, V., \& Krueger, H. P. (2010). Meta-analysis of empirical studies concerning the effects of alcohol on safe driving EU Project DRUID, WP 1, Deliverable 1.1.2a.

Sivak, M. (1996). The information that drivers use: Is it indeed 90\% visual? Perception, 25 (9), 1081-1089.

Underwood, G. (2007). Visual attention and the transition from novice to advanced driver. Ergonomics, 50(8), 1235-49. doi:10.1080/00140130701318707

Wickens, C.D. (1984). Processing resources in attention. In R. Parasuraman \& D.R. Davies (Eds), Varieties of attention. New York : Academic Press.

Wickens, C.D. (2002). Multiple ressources and performance prediction. Theoretical Issues in Ergonomics Sciences 3 (2), 159-177.

Williams, L. J. (2009). The International Journal of Aviation Psychology Peripheral Target Recognition and Visual Field Narrowing in Aviators and Nonaviators, (March 2013), 37-41.

Williams, L.J. (1995). Peripherical target recognition and visual field narrowing in aviators and non aviators. The International Journal of Aviation Psychology 5 (2), 215-232.

Young, K.L., Salmon, P.M. (2012). Examining the relationship between driver distraction and driving errors : A discussion of theory, studies and methods. Safety Science 50 (2), 165-174.

Zador, P.L., Krawchuk, S.A. and Voas, R.B. (2000). Alcohol related relative risk of driver fatalities and driving involvement in fatal crashes in relation to driver age and gender : an update using the 1996 data. Journal of Study Alcohol 61 (3), 387-395. 